\title{
Functional neurological deficit increased the risk of death in childhood epilepsy
}

\author{
Camfield CS, Camfield PR, Veugelers PJ. Death in children with epilepsy: a population-based study. Lancet \\ 2002;359:1891-5.

\section{QUESTION: What are the risk factors for, and frequency of, all cause mortality in children with epilepsy?}

\section{Design}

Inception cohort of children who developed epilepsy between 1977 and 1985 and were followed up for $\leq 22.5$ years.

\section{Setting}

Nova Scotia, Canada.

\section{Patients}

692 children ( $50 \%$ girls) who developed epilepsy (first 2 unprovoked seizures) between 1977 and 1985 (age range $28 \mathrm{~d}$ to $16 \mathrm{y}$ ). Exclusion criteria included provoking factors for seizures and evidence of progressive neurological disease.

\section{Assessment of prognostic factors}

In 1999, names and birth dates of the cohort were linked to the Nova Scotia provincial death and marriage registries (Division of Vital Statistics). For women $>15$ years of age, the marriage registry was checked to ascertain whether the names had been changed by marriage, and the marriage name was also checked against the death registry. Death certificates, necropsy reports, and physician records of children who had died were examined, and families were contacted to verify if sudden unexpected death in epilepsy (SUDEP) could have occurred. Duration of follow up of survivors was established by the last date they were known to be alive. Association between prognostic factors and mortality was assessed using univariate and multivariate analyses.

\section{Main outcome measure}

Incidence of all cause mortality in childhood epilepsy.

\section{Main results}

$3.8 \%$ of children with epilepsy died. Incidence of all cause mortality was greater in the study cohort than in the general population of Nova Scotia (standardised mortality ratio for $1980-895.30,95 \%$ CI 2.29 to 8.32 , and for 1990-99 8.80, CI 4.16 to 13.43). Kaplan-Meier curves showed a mortality rate of $6.1 \%$ at 20 years after onset of epilepsy compared with $0.88 \%$ in the reference population. Both univariate and multivariate analyses showed that the incidence of all cause mortality was greater in children who had sufficient disorders to cause functional neurological deficit (FND) than in those who did not (table). Univariate analysis showed that age at onset and type of epilepsy were associated with all cause mortality. However, this effect diminished after adjusting for neurological deficit (table). In fact, the overall rate of death of patients without severe neurological deficit did not differ from the estimated Kaplan-Meier population rate in the reference population.

\section{Conclusion}

Children with epilepsy, but without functional neurological deficit, had a similar risk of death to that of the general population; however, children with epilepsy who also had other severe neurological disorders had an increased risk of death.

Source of funding: no external funding.

For correspondence:

Dr C S Camfield,

Division of Child

Neurology, IWK Health

Centre, Halifax, Nova

Scotia, B3J 369 ,

Canada.

Association between all cause mortality and prognostic factors in children with epilepsy*

\begin{tabular}{llll} 
Prognostic factor & Comparison & $\begin{array}{l}\text { Univariate RR } \\
(95 \% \mathrm{Cl})\end{array}$ & $\begin{array}{l}\text { Multivariate RR } \\
(\mathrm{Cl}) \dagger\end{array}$ \\
Sex & Girl $v$ boy & $1.5(0.7$ to 3.2$)$ & $1.3(0.6$ to 2.9$)$ \\
\hline Age at onset $(\mathrm{y})$ & $1-5 v 0$ & $0.9(0.3$ to 1.5$)$ & $1.5(0.6$ to 3.9$)$ \\
\hline Epilepsy type & $6-16 v 0$ & $0.3(0.1$ to 0.8$)$ & $1.7(0.5$ to 6.1$)$ \\
\hline & $\begin{array}{l}\text { Generalised or } \\
\text { partial SG } v \text { SG }\end{array}$ & $0.2(0.1$ to 0.5$)$ & $0.7(0.3$ to 1.7$)$ \\
\hline Neurological disorder & SND $v$ none & $0.1(0.0$ to 0.6$)$ & $0.8(0.1$ to 8.1$)$ \\
\hline
\end{tabular}

*SG = secondary generalised epilepsy; SND = severe neurological disorder. RR and Cl defined in glossary. tMultivariate RRs are adjusted for other prognostic factors.

\section{COMMENTARY}

The study by Camfield $e t$ al found that children with epilepsy, but without FND, had a similar risk of death to that of the general population. On the other hand, those with severe neurological disorders had a marked increase in the risk of death. These results are consistent with a study by Callenbach $e t$ al who found that children with non-symptomatic epilepsy did not have an increased mortality risk compared with the general population, whereas those with symptomatic epilepsy had a 20 -fold increase in mortality risk. ${ }^{1}$

It is important to distinguish between SUDEP and death in children with epilepsy. SUDEP is the "sudden, unexpected, witnessed or unwitnessed, non-traumatic and nondrowning death in patients with epilepsy, with or without evidence for a seizure, and excluding documented status epilepticus, in which post-mortem examination does not reveal a toxicological or anatomical cause for death". ${ }^{2}$ Of the 26 deaths reported by Camfield $e t$ al, 22 were not unexpected and resulted from severe disorders sufficient to cause FND. 4 deaths were SUDEP, which is consistent with the findings of Callenbach $e t$ al. ${ }^{1}$ However, the National Sentinel Clinical Audit of Epilepsy-Related Death in the UK recently concluded that it is difficult to establish the true number and nature of epilepsy related deaths from records because a high percentage of epilepsy related deaths are inadequately investigated. ${ }^{2}$ They recommend that the quality of death certification in these deaths should be improved.

Strengths of the study by Camfield et al include lengthy follow up of a large cohort of children, exclusion of those with progressive neurological disease, and the robust multivariate analysis that isolated the dramatic influence of neurological deficit on the mortality rates.

The results of this study provide guidance for counselling parents of children who have epilepsy. Parents can be reassured that most deaths are not related to the epilepsy but rather to comorbid neurological disorders sufficient to cause FND.

Linda Perry, RGN, RSCN Director of Medical Services The National Centre for Young People with Epilepsy, Lingfield, Surrey, UK

1 Callenbach PM, Westendorp RG, Geerts AT, et al. Mortality risk in children with epilepsy: the Dutch study of epilepsy in childhood. Pediatrics 2001;107:1259-63. 2 Hanna NJ, Black M, Sander JW, et al. The National Sentinel Clinical Audit of

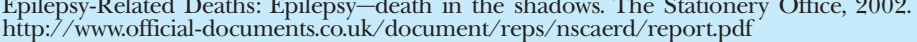

